\title{
An overview of analgesics: NSAIDs, paracetamol, and topical analgesics \\ Part 1
}

\section{R van Rensburg, H Reuter}

Division of Clinical Pharmacology, Department of Medicine, Faculty of Medicine and Health Sciences, Stellenbosch University, Cape Town *Corresponding author, email: rolandmed@gmail.com

\begin{abstract}
Pain is a complex and unique experience. It encompasses several pathways, involving nociceptive signal generation (transduction) and propagation (transmission), as well as perception and modulation of the nociceptive stimuli. Nonsteroidal anti-inflammatory drugs (NSAIDs) primarily exert their analgesic effects through inhibition of cyclooxygenase (COX) enzymes, thereby attenuating prostaglandin synthesis. The COX-2 selective NSAIDs (coxibs) and aspirin have also been shown to reduce colorectal cancers, presumably by prostaglandin-inhibition mechanisms. Paracetamol appears to have both peripheral and central effects. The postulated mechanism for its peripheral effects is indirect COX inhibition, while the central effects are thought to be mediated by modulation of descending pain inhibition pathways. Topical analgesics are available in various formulations. The topical NSAIDs have the same mechanism of action as the systemic formulations, but with less systemic absorption and effects. The local anaesthetics provide a dense sensory block via inhibition of nerve impulse transmission, and are available in percutaneous and transdermal preparations. Capsicum is effective for neuropathic pain, and acts by stimulating and then desensitising peripheral sensory nerves.
\end{abstract}

Keywords: Pain, nociception, NSAIDs, paracetamol, topical analgesia

\section{Introduction}

Pain is a complex and uniquely personal experience, involving various physiological and perceptual pathways and factors. Pain is distinct from nociception, the latter being defined as the transmission of noxious stimuli to the brain, and the numerous processes that drive this transmission. ${ }^{1}$ Pain is then accordingly described as perceiving nociception, whether arising from the nociceptors (nociceptive pain), the nerve itself (neuropathic pain), or a combination of the two (mixed pain). Pain is further defined as "an unpleasant sensory and emotional experience associated with actual or potential tissue damage, or described in terms of such damage,"2 and is therefore an experience by an individual that involves both perceptual and physiological input.

The experience of pain as we currently understand it can be broadly divided into four steps: transduction, transmission, modulation, and perception ${ }^{1}$ (Figure 1). Transduction involves the stimulation of nociceptors at tissue sites by various noxious stimuli. Transmission carries the induced action potentials via fast A-delta and slower C fibres to the dorsal horn of the spinal cord, and further on to the thalamus and finally the cerebral cortex. Modulation of nociceptive signals occurs by stimulation of descending inhibitory pathways from the brain and brainstem, thereby altering afferent signals that eventually reach the brain to be interpreted. ${ }^{3}$ Perception of nociceptive signals is very complex, and occurs primarily in the somatosensory, prefrontal, insular, and cingulate cortices. ${ }^{3}$

Pain management can be targeted at any of the above pathways (or combinations thereof) and the most suitable treatment

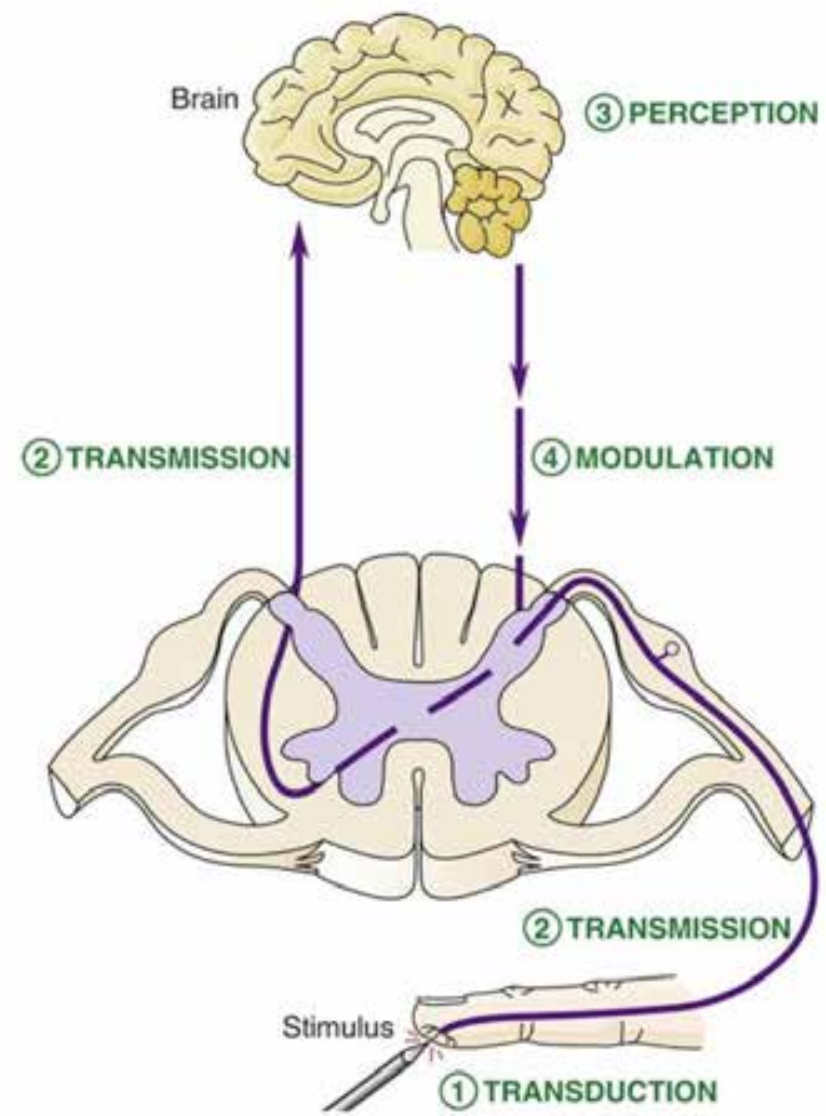

Figure 1: Nociceptive and pain pathways ${ }^{4}$ 
modality will be determined by the type of pain, patient and disease factors, drug characteristics, efficacy, and tolerability. This 3-part series on analgesics will cover different classes of treatments used in pain management, and will discuss the mechanisms of action and place in therapy of the nonsteroidal anti-inflammatory drugs (NSAIDs), paracetamol, and topical analgesics (Part 1), opioids, tramadol, and tapentadol (Part 2), and antidepressants and anticonvulsants (Part 3).

\section{Nonsteroidal anti-inflammatory drugs (NSAIDs)}

\section{Mechanism of action}

The NSAIDs comprise a heterogenous group of six major chemical classes of drugs that are primarily used as anti-inflammatory agents. The main mechanism of action of NSAIDs is inhibition of the formation of prostaglandins (as well as prostacyclin and thromboxane) from arachidonic acid via inhibition of cyclooxygenase enzymes 1 and 2 (COX-1 and COX-2, also known as prostaglandin synthase), ${ }^{5}$ (Figure 2 ). The nomenclature of the COX enzymes is slightly misleading, as the synthase enzyme has both a cyclooxygenase (COX) and a peroxidase (POX) binding site. ${ }^{6}$

The COX-1 enzyme is variably expressed in nearly all tissues, and is responsible for regulating normal cellular processes.? COX-2 is generally undetectable in most tissues - except for its constitutive expression in the brain, kidney, and bone - but is highly inducible in states of inflammation, leading to the production of proinflammatory prostaglandins. ${ }^{7}$ While many processes contribute to the establishment of inflammation, the prostaglandins are putatively accepted as the primary inflammatory mediators. The various downstream effects of prostaglandin synthesis depend on the differential expression of COX-1 and COX-2 enzymes in different tissues at the sites of inflammation. ${ }^{8}$

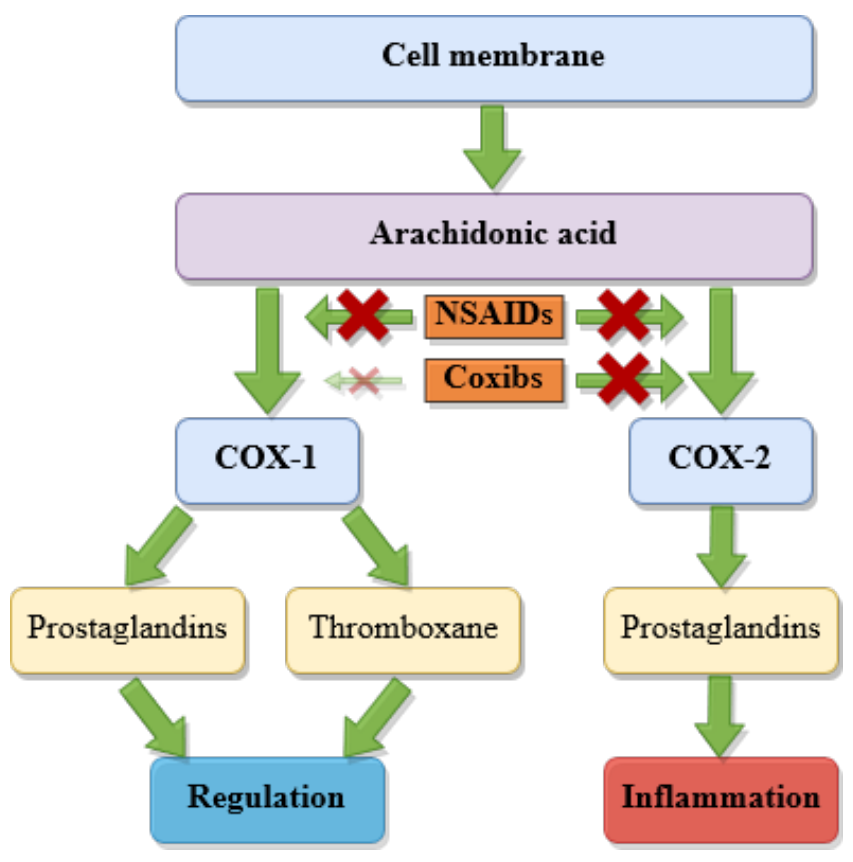

Figure 2: NSAID-mediated COX inhibition

COX - Cyclooxygenase

Coxib - Selective COX-2 inhibitor

NSAIDs - Nonsteroidal anti-inflammatory drugs
NSAIDs exert their effect through the inhibition of COX enzymes, thereby reducing the production of prostaglandins and diminishing nociceptive signal transduction. The selection and degree of COX inhibition varies, however, depending on the NSAID used. ${ }^{9}$ Non-selective NSAIDs, including the oxicams, inhibit both COX-1 and COX-2, whereas the more selective COX2 inhibitors (termed "coxibs") have a much greater affinity for the COX-2 enzyme. ${ }^{10}$ However, apart from some data on the coxibs, the degree of inhibition - and even COX selectivity correlates poorly with the degree of anti-inflammatory effects. ${ }^{9}$ Consequently, while the role of COX-2 in inflammation is putatively considered to be integral, the effect of the enzyme's inhibition on inflammation is not completely understood.

\section{Place in therapy}

The clinical efficacy of NSAIDs at equipotent doses is similar in the general population. ${ }^{11}$ Yet among individuals there is considerable variation of the different NSAIDs with regards to response and adverse effects. ${ }^{12}$ This is most likely due to drug factors, like differences in the COX-selectivity of drugs, or patient factors, like genetically-determined differences in individuals' pharmacokinetics and pharmacodynamics. ${ }^{13}$

The effect of prostaglandin inhibition by NSAIDs has been shown to extend beyond inflammation-related applications, most notably the reduction of colorectal cancers. Several large systematic reviews and meta-analyses have shown that NSAID use is associated with a lower incidence of benign and malignant colorectal tumours, with the reduction estimated to be in the range of $20-40 \% .^{14,15,16}$ These studies focused primarily on aspirin and the coxibs, but the application may extend to other NSAIDs as well. Colonic tumorigenesis appears to be associated with prostaglandin synthesis via tumour angiogenesis, cell proliferation, and inhibition of apoptosis. ${ }^{17}$ Inhibition of COX with NSAIDs may oppose these effects, thereby preventing tumorigenesis and inducing apoptosis. This has formed the rationale for adding celecoxib, a more selective COX-2 inhibitor, to the treatment regimen of chemotherapy-resistant cancers. ${ }^{18}$

The effect of NSAIDs on the inhibition of inflammation also appears to be influenced by non-prostaglandin-mediated effects. The clinical relevance of these effects is still under investigation, but seems to be facilitated by inhibition of neutrophils ${ }^{19}$ and disruption of protein interactions in cell membranes. ${ }^{20}$

Inhibition of COX enzymes is also responsible for the adverse effects of NSAIDs, most notably gastrointestinal ulceration, and cardiovascular events. A 2013 meta-analysis of > 350000 participants has indicated that diclofenac and the coxibs were associated with a small increased risk of major cardiovascular events ( 2 events per 1000 patient-years). ${ }^{21}$ This effect appears to be mediated by a shift in the balance between COX-1 and COX-2 inhibition. As the coxibs primarily inhibit COX-2, there is a shift to the more unopposed COX-1 thromboxane effects, which are vasoconstrictive and pro-aggregatory.22 This theory has been contested in recent years, as the more COX-1 selective NSAIDs - tipping the balance more equally for the COX enzymes - are not all associated with a lower incidence of cardiovascular 
events. $^{22}$ Furthermore, the addition of aspirin to the coxibs to antagonise the COX-1 and thromboxane effects has not resulted in significantly decreased cardiovascular events. ${ }^{22}$ NSAIDs should also be used with caution in at-risk patients for renal, pulmonary, dermatological, and haematological adverse effects. ${ }^{23}$ Nonetheless, NSAIDs are generally regarded as safe if used for short periods at the lowest effective dose. The beneficial outcomes of low-dose aspirin (75-100 mg) on the prevention of vascular events, however, have been well described. To date, a one-dose-fits-all approach has generally been employed, but recent evidence suggests that this may not be the optimal strategy. An analysis of trials including $>117000$ participants found that low-dose aspirin was most effective in prevention of vascular events in participants weighing $<70 \mathrm{~kg}$, whereas participants weighing $\geq 70 \mathrm{~kg}$ benefited most from aspirin doses of $\geq 325 \mathrm{mg}^{.24}$

In clinical practice the selection of a specific NSAID will depend on various factors, including the indication and evidence-base for a specific NSAID's use, adverse effect profile, and patient experience and preference. The need for long-term NSAID therapy (including the coxibs) must be re-evaluated often, and switching between NSAIDs may be warranted to achieve the best outcome for a patient given the known variability in individual response to different NSAIDs.

\section{Paracetamol}

Paracetamol is one of the world's most widely used analgesics, and despite its ubiquitous use, the mechanism by which it elicits pain relief is not fully understood. It was previously thought that paracetamol does not inhibit prostaglandin synthesis, despite its pharmacological and toxicological effects indicating so. However, research in the last two decades suggests that it does indeed inhibit prostaglandin production, but only when low levels of inflammation are present. ${ }^{25}$ In clinical care paracetamol is usually effective for the pain associated with mild to moderate inflammation, such as sprains and contusions, but not in patients experiencing significant inflammation associated with rheumatoid arthritis or acute gout. The postulated explanation for this observation is the indirect inhibition of the COX enzymes via inhibition of its POX binding site, thereby reducing the activity at the COX site. ${ }^{6,25}$ This is in contrast to the direct inhibition of the COX binding sites with the NSAIDs and coxibs.

The analgesic effects of paracetamol appear to be mediated through both peripheral and central mechanisms. Peripherally, the reduction in prostaglandin synthesis reduces transduction of the sensory nerves, leading to decreased nociceptive impulse transmission. Centrally, paracetamol inhibits the increase in central nervous system prostaglandins that are induced by peripheral nociceptive transmission..$^{25}$ Paracetamol appears to have some COX-2 selectivity, as evidenced by its favourable gastrointestinal tolerance and minimal effect on platelets, primarily COX-1-mediated effects. ${ }^{25}$ It was postulated that paracetamol inhibits COX-3, a splice variant of $\mathrm{COX}-1,{ }^{26}$ but subsequent evidence refuted the clinical relevance of this proposed inhibition. ${ }^{25,27}$ Other central analgesic mechanisms of paracetamol have been proposed and these relate to stimulation of opioid receptors, as opioid antagonists in animal models reverse the analgesic activity of paracetamol.6,25 This effect may be mediated by opioid receptor agonism in the brain, and possibly also by stimulating opioid-driven descending inhibition pathways in the spinal cord. ${ }^{1}$ Paracetamol may also activate serotonin-related descending inhibition pathways in the spinal cord, thereby modulating nociception. ${ }^{6}$ Paracetamol has also been linked to activation of the endogenous cannabinoid system, primarily via one of its active metabolites. ${ }^{6,28}$

Paracetamol is widely used in mild to moderate pain with good efficacy and low toxicity at therapeutic doses. Given that the effects of paracetamol on the body is not yet fully understood, future research may uncover interesting mechanisms of action, particularly relating to the endogenous cannabinoid system.

\section{Topicals analgesics}

Topical analgesics are indicated for the relief of mild to moderate muscle and joint pain, and include the topical NSAIDs (including salicylates), capsicum, and local anaesthetics (LA). The latter are used to produce a dense sensory block for local procedures or pain relief. Topical analgesics exert their effects either by reducing transduction (NSAIDs, capsicum) or transmission (LA) of nociceptive signals.

The LAs are available as percutaneous injections, or formulated as transdermal creams, gels, sprays, or patches. They cause a sensory block by inhibiting sodium channels in nerve axons, thereby preventing generation and propagation of nerve impulses. ${ }^{29}$ It inhibits these ion channels from the cytoplasmic side of the axon, and therefore the drug molecule first has to pass through the membrane in the permeable, unionised form. Conditions that make the local environment more acidic, such as abscesses, will decrease the amount of unionised drug, and reduce the analgesic effect.' 'LAs also bind to potassium channels in nerves, but require much larger doses to significantly block these channels. ${ }^{30}$ Of note is that the LAs affect nociceptive sensory nerves and autonomic nerves much more readily than motor nerves. It was previously thought that this observation was due to the LAs affecting smaller diameter sensory fibres more than the larger diameter motor fibres. ${ }^{31}$ Newer evidence indicates that it is rather the distance between the nodes of Ranvier of myelinated nerves that designate a nerve's susceptibility to be blocked, with the shorter-spaced nodes of the nociceptive fibres being more readily affected. ${ }^{29}$

Topical NSAIDs have the same mechanism of action as the systemic formulations. Penetration through the skin to the site of inflammation leads to a more focused site of drug action. Systemic absorption and subsequent adverse effects are lessened with topical preparations, but these systemic effects should always be borne in mind when prescribing topical NSAIDs. A recently updated Cochrane Review ${ }^{32}$ comparing 16 topical NSAIDs to placebo for clinically significant acute musculoskeletal pain relief found that diclofenac, ketoprofen, and ibuprofen were most effective (number needed to treat [NNT] of less than 4). All other topical NSAIDs had an NNT of greater than 4, indicating 
lesser efficacy. Topical NSAIDs were also more efficacious in mild to moderate acute pain conditions, with limited effect in chronic musculoskeletal pain. In another Cochrane Review ${ }^{33}$ the salicylate preparations, such as methyl salicylate, showed conflicting evidence, with the older, smaller studies indicating efficacy, whereas the newer, larger trials did not.

Capsicum is approved for the temporary relief of neuropathic pain, as well as minor muscle and joint pain. It acts on the slow, sensory C-fibres where it first stimulates (causing an intense burning pain), and then desensitises the nerve. ${ }^{34}$ Capsicum also appears to deplete substance $P$, an endogenous neuropeptide involved in nociceptive transduction and transmission. ${ }^{35}$ Evidence for the efficacy of capsicum was published in a recent review, ${ }^{36}$ and found that high-concentration capsicum (8\%) was effective for neuropathic pain relief.

Topical analgesia may serve as a single pharmacological modality in mild to moderate pain relief, or as part of a multimodal pain management strategy to reduce pill burden or adverse effects while still providing analgesia. The potential of the topicals to alter pain perception and modulation must also not be overlooked, as simply the act of applying a cream, gel, or plaster may provide pain relief unrelated to the drug itself.

\section{Conclusion}

NSAIDs, paracetamol, and the topical analgesics provide effective and generally safe options for mild to moderate pain. Alterations of peripheral nociceptive transduction and transmission are the main targets of effect, with paracetamol possibly modulating central pain pathways as well. All analgesic classes have a place in therapy, but this is guided by the type and severity of pain, the evidence-base for its use, and the patient and drug profiles.

\section{References}

1. Answine JF. A Basic Review of Pain Pathways and Analgesia [Internet]. New York; 2018. Available from: https://www.anesthesiologynews.com/Review-Articles/ Article/10-18/A-Basic-Review-of-Pain-Pathways-and-Analgesia/52868

2. Merskey H, Bogduk N. IASP Terminology - IASP [Internet]. IASP task force on taxonomy. [Accessed 28 Nov 2018]. Available from: http://www.iasp-pain.org/ Education/Content.aspx?ltemNumber=1698\#Pain

3. Almeida $T F$, Roizenblatt $S$, Tufik $S$. Afferent pain pathways: a neuroanatomical review. Brain Res [Internet]. 12 Mar 2004 [Accessed 28 Nov 2018];1000(1-2):4056. Available from: https://www-sciencedirect-com.ez.sun.ac.za/science/article/ pii/S0006899304001052

4. Marsh JD. Pain [Internet]. Basicmedical Key. 2016 [Accessed 7 Jan 2019]. Available from: https://basicmedicalkey.com/pain-3/

5. Vane JR. Inhibition of prostaglandin synthesis as a mechanism of action for aspirin-like drugs. Nat New Biol [Internet]. 23 Jun 1971 [Accessed on 18 Dec 2018];231(25):232-5. Available from: http://www.ncbi.nlm.nih.gov/ pubmed/5284360

6. Smith HS. Potential analgesic mechanisms of acetaminophen. Pain Physician. 2009;12(1):269-80.

7. Dubois RN, Abramson SB, Crofford L, Gupta RA, Simon LS, Van De Putte LB, et al. Cyclooxygenase in biology and disease. FASEB J [Internet]. Sep 1998 [Accessed on 18 Dec 2018];12(12):1063-73. Available from: http://www.ncbi.nlm.nih.gov/ pubmed/9737710

8. Ricciotti E, FitzGerald GA. Prostaglandins and inflammation. Arterioscler Thromb Vasc Biol [Internet]. May 2011 [Accessed on 28 Dec 2018];31(5):986-1000. Available from: http://www.ncbi.nlm.nih.gov/pubmed/21508345

9. Oates JA, Wood AJJ, Brooks PM, Day RO. Nonsteroidal Antiinflammatory Drugs — Differences and Similarities. N Engl J Med [Internet]. 13 Jun 1991 [Accessed on 18 Dec 2018];324(24):1716-25. Available from: http://www.nejm.org/doi/ abs/10.1056/NEJM199106133242407

10. FitzGerald GA, Patrono C. The Coxibs, Selective Inhibitors of Cyclooxygenase-2. Wood AJJ, editor. N Engl J Med [Internet]. 9 Aug 2001 [Accessed on19 Dec 2018];345(6):433-42. Available from: http://www.nejm.org/doi/10.1056/ NEJM200108093450607

11. Agency for Healthcare Research and Quality. Comparative Effectiveness Review Number 38. Analgesics for osteoarthritis: An update of the 2006 comparative effectiveness review. Executive summary. [Internet]. [Accessed on 19 Dec 2018]. Available from: https://effectivehealthcare.ahrq.gov/sites/default/files/related files/osteoarthritis-pain_executive.pdf

12. Furst $D E$. Are there differences among nonsteroidal antiinflammatory drugs? Comparing Acetylated Salicylates, Nonacetylated Salicylates, and Nonacetylated Nonsteroidal Antiinflammatory Drugs [Internet]. Arthritis \& Rheumatism. 1994. [Accessed on 19 Dec 2018];37. Available from: https://onlinelibrary.wiley.com/ doi/pdf/10.1002/art.1780370102

13. Bruno A, Tacconelli S, Patrignani P. Variability in the Response to Non-Steroidal Anti-Inflammatory Drugs: Mechanisms and Perspectives. Basic Clin Pharmacol Toxicol [Internet]. 2013 [Accessed on 8 Jan 2019];114:56-63. Available from: https://onlinelibrary.wiley.com/doi/pdf/10.1111/bcpt.12117

14. Dubé C, Rostom A, Lewin G, Tsertsvadze A, Barrowman N, Code C, et al. The Use of Aspirin for Primary Prevention of Colorectal Cancer: A Systematic Review Prepared for the U.S. Preventive Services Task Force. Ann Intern Med [Internet]. 6 Mar 2007 [Accessed 20 Dec 2018];146(5):365. Available from: http://annals.org/ article.aspx?doi=10.7326/0003-4819-146-5-200703060-00009

15. Rostom A, Dubé C, Lewin G, Tsertsvadze A, Barrowman N, Code C, et al. Nonsteroidal Anti-inflammatory Drugs and Cyclooxygenase-2 Inhibitors for Primary Prevention of Colorectal Cancer: A Systematic Review Prepared for the U.S. Preventive Services Task Force. Ann Intern Med [Internet]. 6 Mar 2007 [Accessed on 20 Dec 2018];146(5):376. Available from: http://annals.org/article. aspx?doi=10.7326/0003-4819-146-5-200703060-00010

16. Cole BF, Logan RF, Halabi S, Benamouzig R, Sandler RS, Grainge MJ, et al. Aspirin for the chemoprevention of colorectal adenomas: meta-analysis of the randomized trials. J Natl Cancer Inst [Internet]. 18 Feb 2009 [Accessed on 20 Dec 2018];101(4):256-66. Available from: http://www.ncbi.nlm.nih.gov/ pubmed/19211452

17. Dannenberg AJ, Lippman SM, Mann JR, Subbaramaiah K, DuBois RN. Cyclooxygenase-2 and epidermal growth factor receptor: pharmacologic targets for chemoprevention. J Clin Oncol [Internet]. 10 Jan 2005 [Accessed on 20 Dec 2018];23(2):254-66. Available from: http://ascopubs.org/doi/10.1200/ JCO.2005.09.112

18. Rosas C, Sinning M, Ferreira A, Fuenzalida M, Lemus D. Celecoxib decreases growth and angiogenesis and promotes apoptosis in a tumor cell line resistant to chemotherapy. Biol Res [Internet]. 2014 [Accessed on 20 Dec 2018];47(1):27. Available from: http://www.biolres.com/content/47/1/27

19. Díaz-González F, González-Alvaro I, Campanero MR, Mollinedo F, del Pozo MA, Muñoz $C$, et al. Prevention of in vitro neutrophil-endothelial attachment through shedding of L-selectin by nonsteroidal antiinflammatory drugs. J Clin Invest [Internet]. Apr 1995 [Accessed on 20 Dec 2018];95(4):1756-65. Available from: http://www.ncbi.nlm.nih.gov/pubmed/7535797

20. Abramson SB, Weissmann $G$. The mechanisms of action of nonsteroidal antiinflammatory drugs. Arthritis Rheum [Internet]. 1 Jan 1989 [Accessed on 20 Dec 2018];32(1):1-9. Available from: http://doi.wiley.com/10.1002/ anr. 1780320102

21. Bhala N, Emberson J, Merhi A, Abramson S, Arber N, Baron J, et al. Vascular and upper gastrointestinal eff ects of non-steroidal anti-infl ammatory drugs: meta-analyses of individual participant data from randomised trials. Lancet [Internet]. 2013 [Accessed on 28 Dec 2018];382(9894):769-79. Available from: http://www.ctsu.

22. Ong CKS, Lirk P, Tan CH, Seymour RA. An Evidence-Based Update on Nonsteroidal Anti-Inflammatory Drugs. Clin Med Res [Internet]. 1 Mar 2007 [Accessed on 28 Dec 2018];5(1):19-34. Available from: http://www.clinmedres. org

23. Tarr GS, Reuter H. Review of the safety of nonsteroidal anti-inflammatory drugs and selective cyclo-oxygenase-2 inhibitors. South African Fam Pract [Internet]. 2015 [Accessed on 28 Dec 2018];57(3):18-22. Available from: www.tandfonline. com/ojp

24. Rothwell PM, Cook NR, Michael Gaziano J, Price JF, F Belch JF, Carla Roncaglioni $\mathrm{M}$, et al. Effects of aspirin on risks of vascular events and cancer according to bodyweight and dose: analysis of individual patient data from randomised 
trials. The Lancet [Internet]. 2018 [Accessed on 20 Dec 2018];392(10145):387-99. Available from: http://dx.doi.org/10.1016/

25. Graham GG, Davies MJ, Day RO, Mohamudally A, Scott KF. The modern pharmacology of paracetamol: therapeutic actions, mechanism of action, metabolism, toxicity and recent pharmacological findings. Inflammopharmacology [Internet]. 30 Jun 2013 [Accessed on 28 Dec 2018];21(3):201-32. Available from: https://link-springer-com.ez.sun.ac.za/ content/pdf/10.1007\%2Fs10787-013-0172-x.pdf

26. Chandrasekharan N V, Dai H, Turepu Roos KL, Evanson NK, Tomsik J, Elton TS, et al. COX-3, a Cyclooxygenase-1 Variant Inhibited by Acetaminophen and Other Analgesic/Antipyretic Drugs: Cloning, Structure, and Expression. Proc Natl Acad Sci USA [Internet]. 2002 [Accessed on 7 Jan 2019];99(21):13926-31. Available from: https://www-jstor-org.ez.sun.ac.za/stable/pdf/3073509.pdf?refreqid=excel sior\%3A8b3b327665c5b9a40002e4ba4f43d49f

27. Graham GG, Scott KF. Mechanism of action of paracetamol. Am J Ther. 2005;12(1):46-55.

28. Ghanem $\mathrm{Cl}$, Pérez MJ, Manautou JE, Mottino AD. Acetaminophen from liver to brain: New insights into drug pharmacological action and toxicity Pharmacol Res [Internet]. 1 Jul 2016 [Accessed on 28 Dec 2018];109:11931. Available from: https://www.sciencedirect.com/science/article/pii/ S1043661816000530?via\%3Dihub

29. Catterall WA, Mackie K. Local anesthetics. In: Brunton LL, Hilal-Dandan R, Knollmann BC, eds. Goodman and Gilman's the pharmacological basis of therapeutics. 13th ed. New York: McGraw-Hill; 2018. p. 406.

30. Strichartz GR, Ritchie JM. The Action of Local Anesthetics on Ion Channels of Excitable Tissues. Local Anesth [Internet]. 1987 [Accessed on 31 Dec 2018];21-52. Available from: http://www.springerlink.com/ index/10.1007/978-3-642-71110-7_2

31. Gasser HS, Erlanger J. The role of fiber size in the establishment of a nerve block by pressure or cocaine. Exp Biol Med [Internet]. 1929 [Accessed on 31 Dec 2018];88(4):581-91. Available from: http://ajplegacy.physiology.org/

32. Derry S, Moore RA, Gaskell H, McIntyre M, Wiffen PJ. Topical NSAIDs for acute musculoskeletal pain in adults. Cochrane Database Syst Rev [Internet]. 2015;(6). Available from: https://doi.org//10.1002/14651858.CD007402.pub3

33. Derry S, Matthews PRL, Wiffen PJ, Moore RA. Salicylate-containing rubefacients for acute and chronic musculoskeletal pain in adults. Cochrane Database Syst Rev [Internet]. 26 Nov2014 [Accessed on 31 Dec 2018];(11). Available from: http://doi.wiley.com/10.1002/14651858.CD007403.pub3

34. Sewell MJ, Burkhart CN, Morrell DS. Dermatological pharmacology. In: Brunton LL, Hilal-Dandan R, Knollmann BC, editors. Goodman and Gilman's the pharmacological basis of therapeutics. 13th ed. New York: McGraw-Hill; 2018. p. 1290.

35. Anand P, Bley K. Topical capsaicin for pain management: therapeutic potential and mechanisms of action of the new high-concentration capsaicin 8\% patch. Br J Anaesth [Internet]. Oct 2011 [Accessed on 31 Dec 2018];107(4):490-502. Available from: http://www.ncbi.nlm.nih.gov/pubmed/21852280

36. Derry S, Rice AS, Cole P, Tan T, Moore RA. Topical capsaicin (high concentration) for chronic neuropathic pain in adults. Cochrane Database Syst Rev [Internet]. 13 Jan 2017 [Accessed on 31 Dec 2018]; Available from: http://doi.wiley. com/10.1002/14651858.CD007393.pub4 